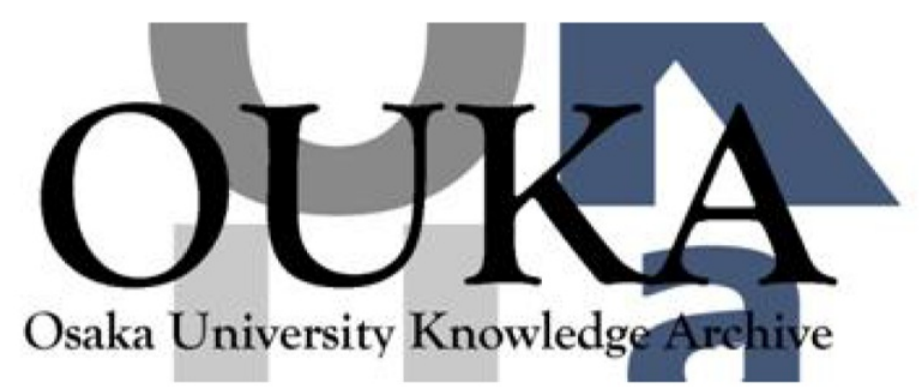

\begin{tabular}{|c|l|}
\hline Title & $\begin{array}{l}\text { Applications of Computer and Numerical Analysis } \\
\text { Techniques in Welding Research }\end{array}$ \\
\hline Author(s) & Ueda, Yukio; Murakawa, Hidekazu \\
\hline Citation & Transactions of JWRI. 13(2) p.337-p. 346 \\
\hline Issue Date & $1984-12$ \\
\hline oaire:version VoR \\
\hline URL & https://doi.org/10.18910/8032 \\
\hline rights & \\
\hline Note & \\
\hline
\end{tabular}

Osaka University Knowledge Archive : OUKA

https://ir. Library. osaka-u. ac. jp/

Osaka University 


\title{
Applications of Computer and Numerical Analysis Techniques in Welding Research $\dagger$
}

\author{
Yukio UEDA* and Hidekazu MURAKAWA***
}

\begin{abstract}
In the recent years, computer technology has made a remarkable progress and a computer has become an indispensable tool not only for engineers but also for scientists. In this report, utilization of computers in welding research is briefly summarized. Especially, its use in numerical analysis is discussed.
\end{abstract}

KEY WORDS (Computer) (Numerical Analysis) (Finite Difference Method) (Finite Element Method) (Monte-Carlo Method) (Stress Analysis) (Three Dimensional Residual Stress Measurement) (Convection and Heat Flow) (Image Processing)

\section{Introduction}

Progress of computer technology in the last two decades has brought remarkable changes to scientific researches. Welding research can not be an exception and computers have become indispensable tools in our researches in various aspects.

In this report, advances in computer technology and utilization of computers in welding research are briefly discussed. Especially, recent developments of numerical analysis in individual fields, such as convection in arc weld pool, hydrogen diffusion in welds, residual stresses and etc., are reviewed in some detail within authors' knowledge.

\section{Computers in Welding Research}

\subsection{Special nature of welding research}

As it is commonly understood, welding engineering is a multidisciplinary technology which encompasses metallurgy, physics, chemistry, electric and electronic engineering, mechanics, and process engineering. Moreover, most of our problems are nonlinear transient and considered in the extreme conditions, such as high temperature and high vacuum. Therefore, the use of analytical approach to clarify the problem is limited to only simple cases. Accordingly, some type of researches greatly depend on human observations and interpretations which may vary from person to person.

$\dagger$ Received on Oct. 30

* Professor

** Research Instructor

\subsection{What computers can do for us}

Reasons for popularization of a computer may be found in its outstanding abilities which compensate human abilities, such as,

a) very fast computing ability

b) huge memory capacity

c) highly reliable reproducibility

d) flexible communication ability.

\subsection{Advances in computer technology}

Computer technology has made a remarkable progress in the last twenty years. Figure 1 shows the progress of computing ability of three different types of computers. Solid circles represent general purpose machines which approximately cost $\$ 5$ million each. As it is seen from the figure, the speed of computation has been increased by ten times every ten years. On the other hand, open circles represent so called super computers which are specially designed for scientific computations. CRAY-1 and Cyber205 belong to this type. Their computation ability is 20 to 30 times higher than that of general purpose machines. CRAY-1, for example, can process more than hundred million instructions per second. Apart from big machines, personal computers in these days, such as HP9000, have become fast enough to be equivalent to big machines of 15 years ago. As far as computing ability is concerned, 1 MIPS is enough to cover $90 \%$ of linear stress analysis required in design work. From this fact alone, we can say computers have become very close to our laboratory or

Transactions of JWRI is published by Welding Research Institute of Osaka University, Ibaraki, Osaka 567, Japan 
design room. However, for problems, such as 3-dimen-

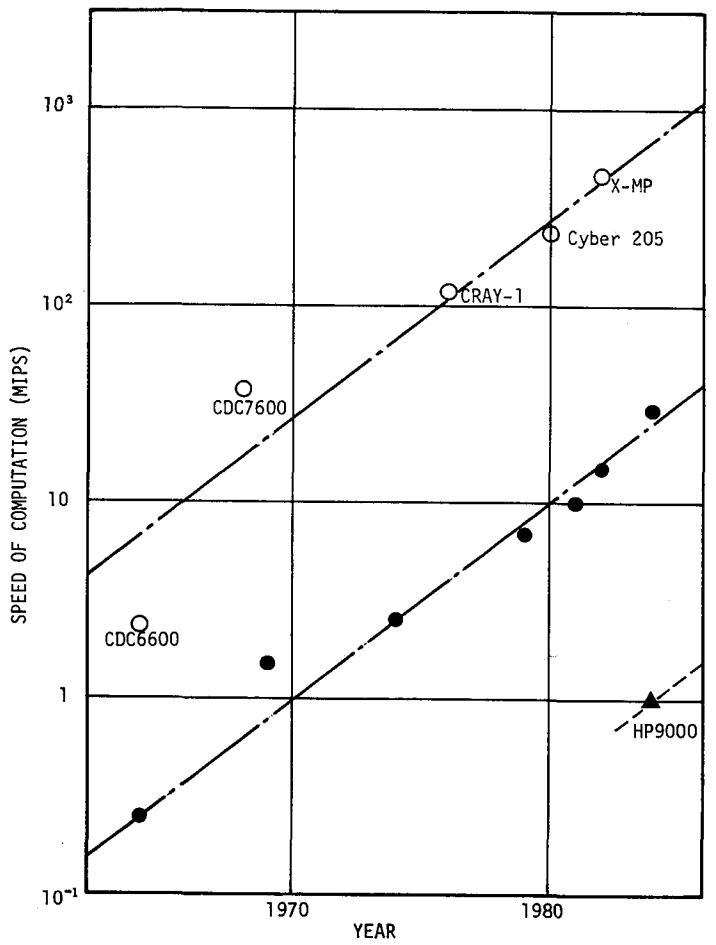

Fig. 1 Advances of computers in terms of computing abilities.

sional nonlinear transient fluid flow or welding stress problems, we still have to depend on super computers.

\subsection{Computer aided engineering in welding}

As it is mentioned in the previous section, recent progress in computer technology provides us wide variety of computers ranging from personal to super computers. Therefore, suitable computer has to be chosen depending on the type of work we are engaged.

Although it may deviate from present subject, let's imagine an ideal computer system in our laboratory. Fig. 2 shows one idea of computer aided engineering system in

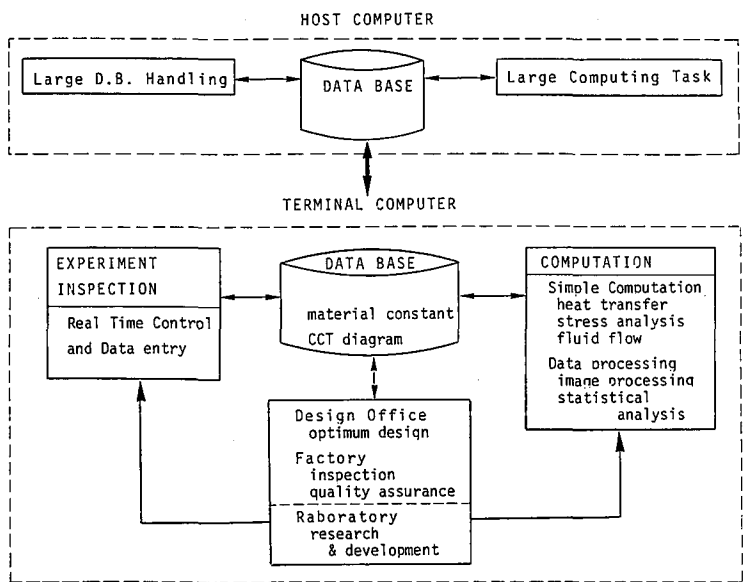

Fig. 2 Computer aided engineering system in welding. welding, in which a big computer and personal computers are integrated into a total system. The host computer may be used for large computing task and large data base handling. On the other hand, personal computer is employed as terminal computer which may be installed in design offices, manufacturing sites, and laboratories. The primary advantage of a personal computer is its availability due to low price. Also, its computational ability which is equivalent to that of general purpose computer of 15 years ago and its capability to construct a data base have to be mentioned. Thus, most computation and data processing can be handled by a personal computer alone. Moreover, if personal computers are connected to experimental and inspection facilities, a total engineering system is constructed. In such a system, automatic testing and inspection can be possible. And also, experimental data can be easily combined with theoretical analysis to achieve simulations of advanced practical problems.

\subsection{Fields of research where computers can be utilized}

Considering the outstanding abilities, computers may be utilized as vital tools in the following fields.

a) Numerical analysis and simulation of physical phenomena

b) Statistical analysis of experimental data

c) Probability and reliability analysis

d) Data base for a vast amount of accumulated experimental data

e) Image data processing and analysis

f) Real time control of experimental apparatuses and manufacturing machines.

\section{Current State of Numerical Analysis}

\subsection{Advantages of numerical analysis}

Numerical analysis is a helpful mean to understand the problem and it has certain advantages over experiments and analytical methods, such as,

a) solutions for complicated practical problems can be easily obtained

b) simulation under extreme conditions including impractical conditions is possible

c) detailed information, which may not be available from experiments, can be provided

d) cost can be less than experiments in some cases.

\subsection{Types of problems and numerical methods}

Problems in which numerical analysis can be a vital mean for the research is listed in Table 1 together with the related physics and numerical methods. Most of the 
Table 1 Types of problems and numerical methods.

\begin{tabular}{|l|l|l|}
\hline \multicolumn{1}{|c|}{ PROBLEMS } & \multicolumn{1}{|c|}{ PHYSICS } & \multicolumn{1}{|c|}{ METHODS } \\
\hline Heat source & Electromagnetics & F.D.M. \\
Molten pool & Heat and mass transfer & F.E.M. \\
Solidification & Phase transformation & Monte-Carlo \\
Residuai stress & Chemical reaction & Molecular Dynamics \\
Cracking & Diffusion & \\
Welding deformation & Elasto-plasticity, Creep & \\
$\begin{array}{l}\text { Strength of welded } \\
\text { structures }\end{array}$ & Failure & \\
\hline
\end{tabular}

problems listed in the table involve more than one physical phenomenon with mutual interactions. Moreover, each physical phenomenon exhibits nonlinear characteristic in many cases.

Concerning the numerical methods, Finite Difference Method is a relatively old but commonly used method to solve partial differential equations in heat and fluid flow problems. On the other hand, Finite Element Method, which can deal with nonlinear behaviors and complex boundary conditions, has been widely used in stress analysis. For the problems involving random process, such as collision of particles, Monte-Carlo method is employed. Typical applications of these numerical methods are reviewed in the following chapter.

\section{Typical Examples}

\subsection{Stress analysis of welded joints}

To ensure the reliability of welded joints, it is very important to estimate the transient and residual stresses associated with welding and stress relief annealing. In general, the phenomena we have to deal with are highly complex and conventional approach is not adequate for the purposes. On the other hand, Finite Element Methods, in which nonlinear behaviors and geometrical complexity can be easily handled, are promissing tools for theoretical analyses. Ueda ${ }^{1,2,3)}$, Fujita $^{4)}$, and Hibbitt ${ }^{5)}$ applied Finite Element Methods to welding. Elaborate review can be found in the report by $\mathrm{Ueda}^{6}$.

As it is discussed in the review ${ }^{6}$, transient and residual stresses in welded joints are produced through complex processes, such as phase transformation and solidification. These processes are considered as results of interactions among temperature, changes in metallurgical properties, and mechanical properties. However, concerning material properties, some of them can be assumed to be independent of others without any loss of accuracy compared to that of experimentally determined properties used in the analysis. Thus, the thermal visco-elastic-plastic problem can be solved as a set of three individual problems, namely,

1. heat conduction analysis
2. metallic structure analysis

3. visco-elastic-plastic analysis.

Apart from the practical applications, precise theoretical discussion on the interaction may be found in the recent report by Inoue $7,8,9$ ).

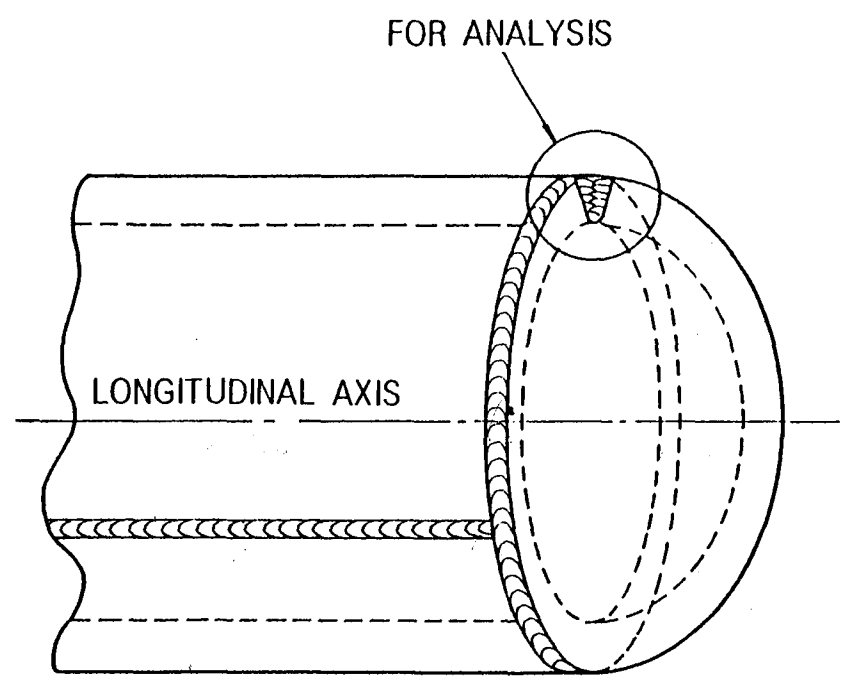

Fig. 3 Welded cylinder-head connection of a pressure vessel.

Fig. 3 shows a welded cylinder-head connection in a pressure vessel which is analyzed as a thermal visco-elasticplastic problem by $\mathrm{Ueda}^{3)}$. The welded joint is idealized as shown by Fig. 4. Also, material properties are idealized.

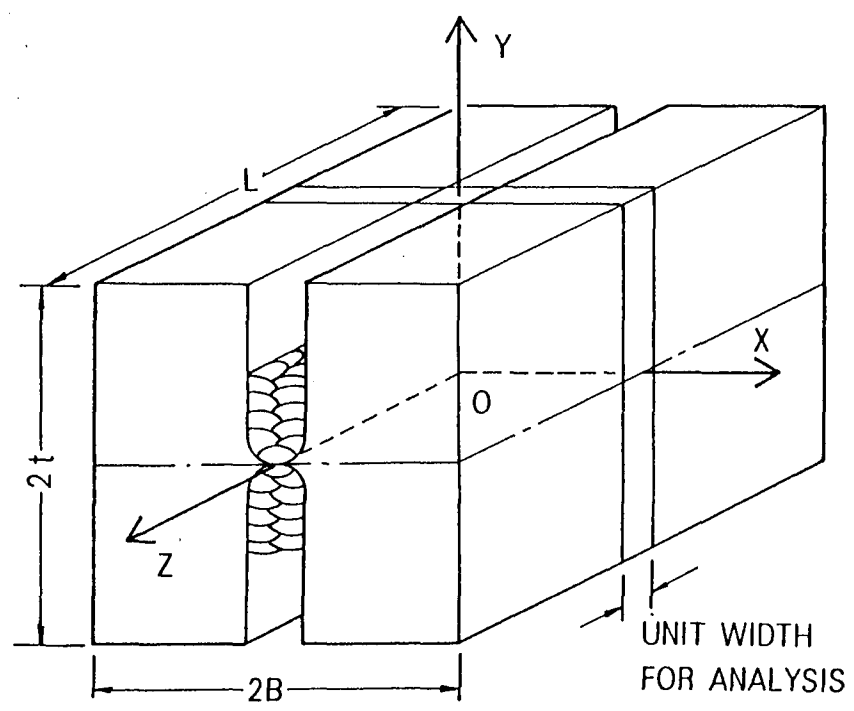

Fig. 4 Idealized research model.

Only the creep law for temperature below $550^{\circ} \mathrm{C}$, which is idealized using strain-hardening model, is shown in Fig. $\mathbf{5}$ as an example. The precise transient and residual stress distributions both by welding and stress relief annealing are analyzed by F.E.M. and further the effectiveness of the stress relief annealing is examined. The final distributions of the residual stresses are compared with experimental measurements in Fig. 6 and very good correlation is observed. 


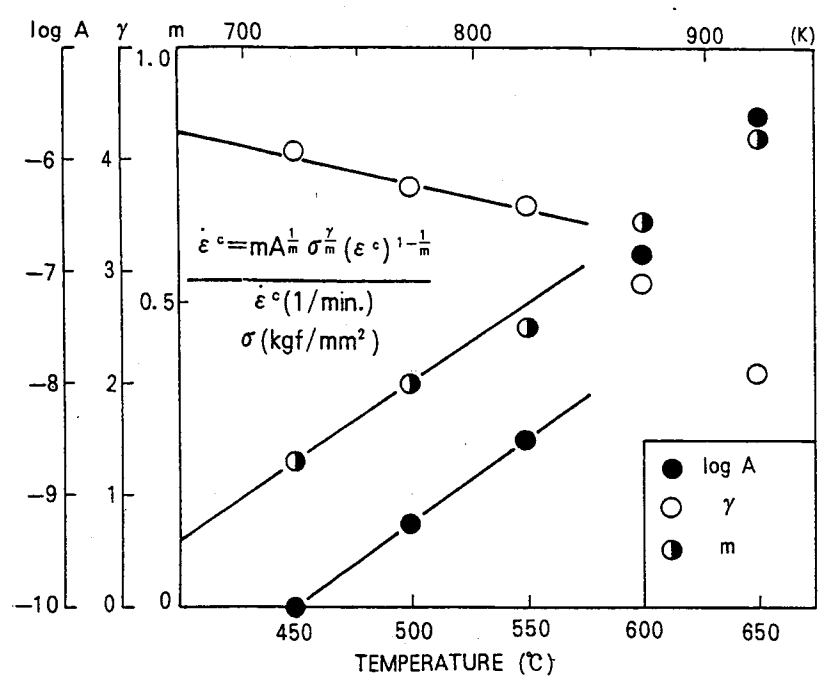

Fig. 5 Idealized creep law for strain-hardening model.

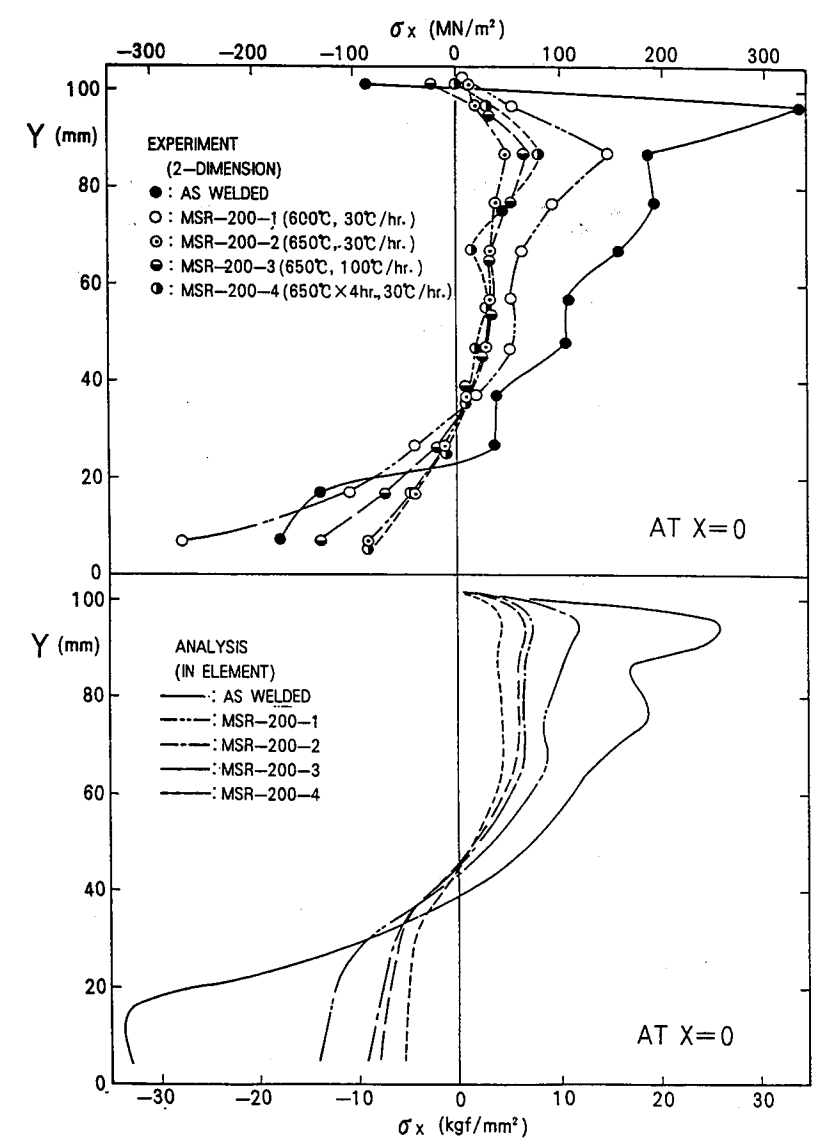

Fig. 6 Transverse residual stresses $\left(\sigma_{\mathrm{X}}\right)$ after annealing at the middle cross section.

\subsection{Measurement of three dimensional welding residual stresses}

The Rosenthal-Norton method is well-known as a technique to measure three dimensional residual stress. This method is based on an assumption that the elastic response of the specimen under slicing follow the simple beam theory. However, this assumption may not be true, in general, for welded joints and it may reduce the accuracy of the measurements in some cases.

A new measuring principle based on the concept of inherent strain, in which no such assumption is required, was proposed by $\mathrm{Ueda}^{10,11)}$. Inherent strain is considered as an essential source of residual stresses and it can be estimated by using F.E.M. from the measured released strains. This principle has been applied to various welded joints ${ }^{12,13,14,15)}$.

If, for example, the weld length is long enough, $\mathrm{L}_{\mathrm{y}}$ and $\mathrm{L}_{\mathrm{Z}}$ methods ${ }^{13)}$ can be used and their procedures are outlined by Fig. 7. When the specimen is sliced into $\mathrm{L}_{\mathrm{y}}$ or

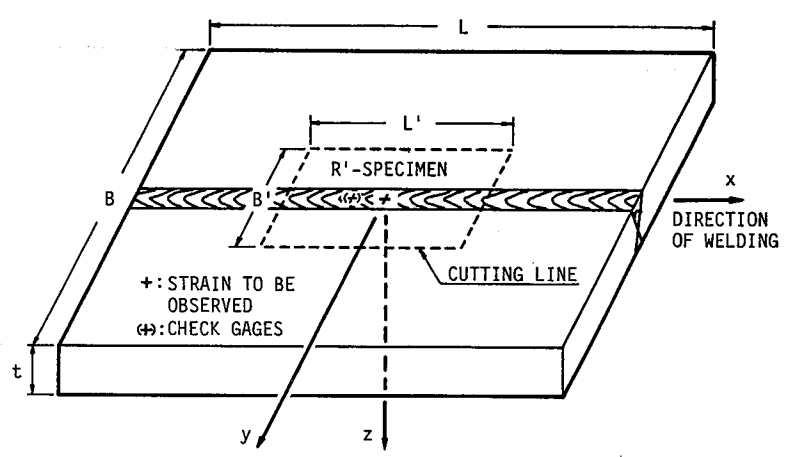

(a) Test model (R-specimen)

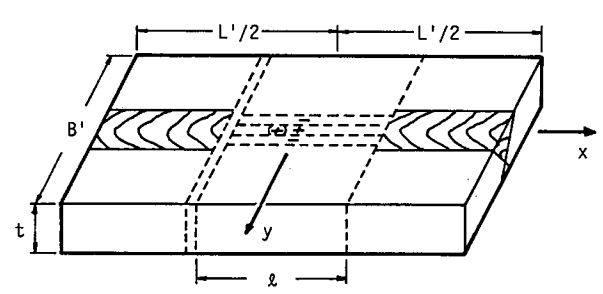

(b) $\mathrm{R}^{\prime}$-specimen produced by cutting

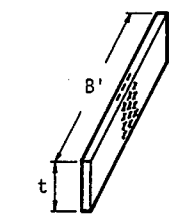

(c) T-specimen

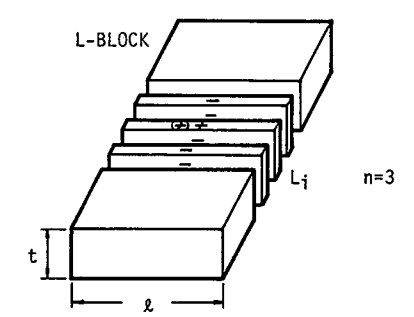

(d) $\mathrm{L}_{\mathrm{i}}$-specimen
$(\ell>2 t)$

Fig. 7 Test model and procedure of slicing $\mathrm{T}$ and $\mathrm{L}_{\mathrm{i}}$-specimens (Ly method).

$\mathrm{L}_{\mathrm{Z}}$ specimens, the interaction between in-plane and out of plane inherent strains can be removed and the problem is reduced to two dimensional problem.

Fig. 8 shows an electroslag welded joint whose residual stresses are measure ${ }^{13}$ ). The estimated residual stresses on the top surface show excellent agreements with the direct measurement as observed in Fig. 9. This demonstrates the accuracy of the method for the entire body of 


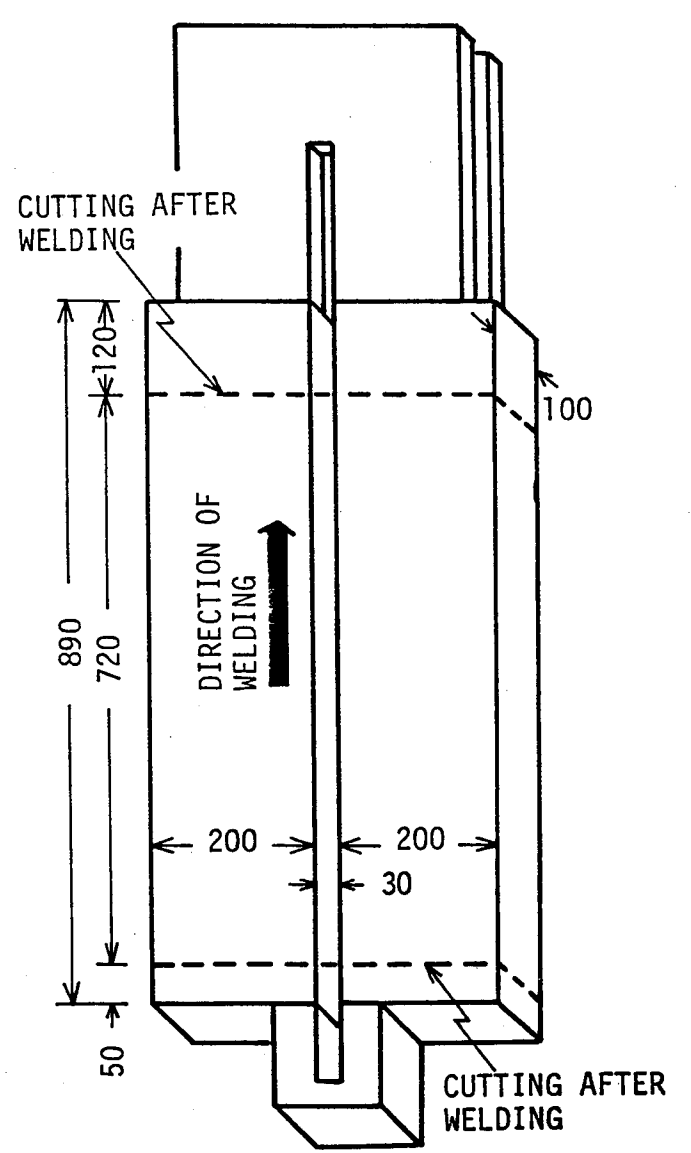

Fig. 8 Test model for electroslag welded joint.

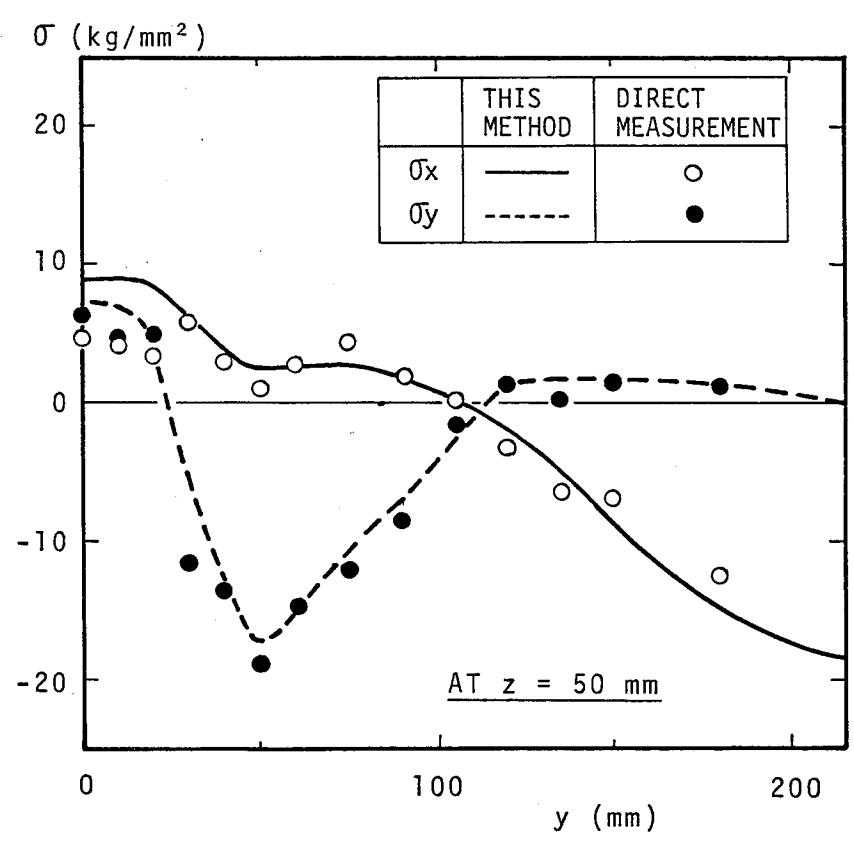

Fig. 9 Welded residual stresses on the surface of R-specimen.

the specimen including the inside. The three dimensional stress distributions in the thickness direction, which can not be measured directly, is estimated as shown by Fig. 10.
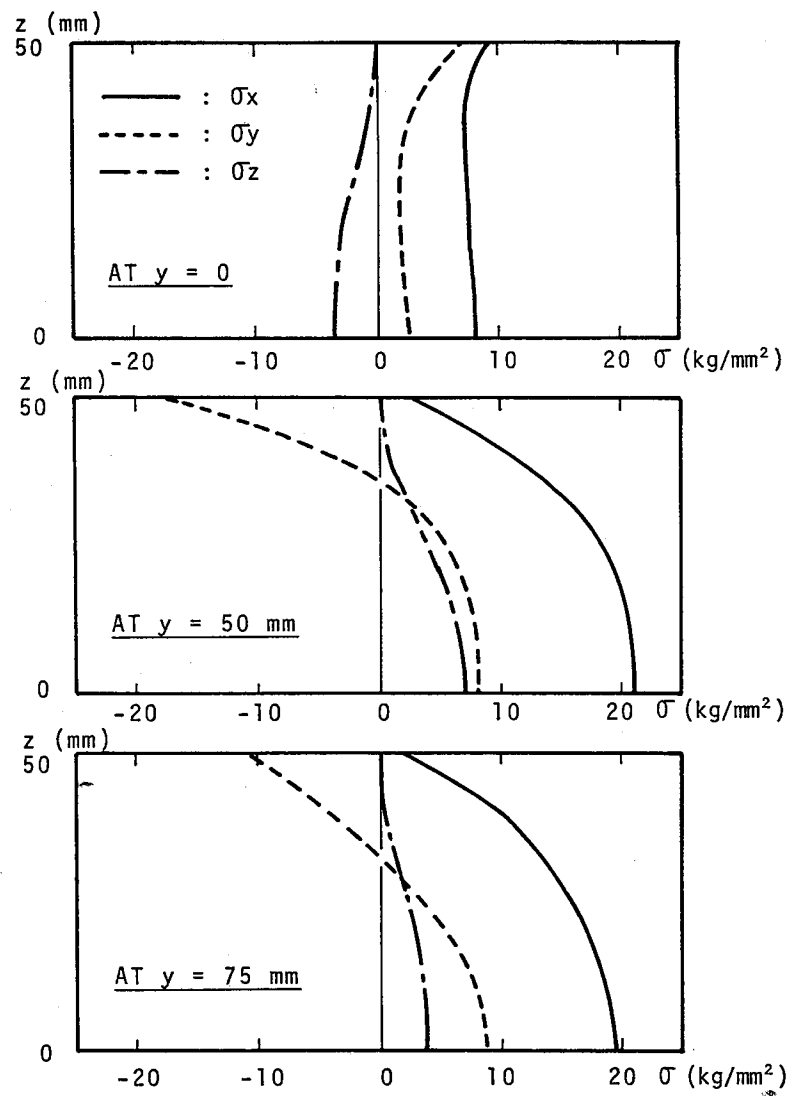

Fig. 10 Estimated residual stresses on the cross section.

\subsection{Convection in arc weld pool}

Finite Element Method has been a powerful tool in stress analysis. On the other hand, Finite Difference Method has been a common numerical method for heat and fluid flow problems. Theoretical analysis in this field has been studied intensively by Szekely ${ }^{16,17)}$ and others $^{18)}$.

The quantitative understanding of convection and heat flow in weld pools is one of considerable practical interest because convective heat flow will affect the weld pool geometry, fume formation, and grain structure in the resulting weld bead. However, the phenomenon is extremely complex because of the possible interactive role played by a number of driving forces.

A numerical analysis of convection and heat flow in an arc weld pool as illustrated by Fig. 11 is reported by Szekely ${ }^{17)}$. The flow in the weld pool is assumed to be driven by buoyancy, surface tension, and electromagnetic forces. The effects of these driving forces on the flow is studied in this example.

Since the phenomenon involves great complexity, certain assumptions must be introduced. And also, informations such as the distribution of the electric current falling on the weld pool is postulated using the experimental measurements. Considering these assumptions, the prob- 


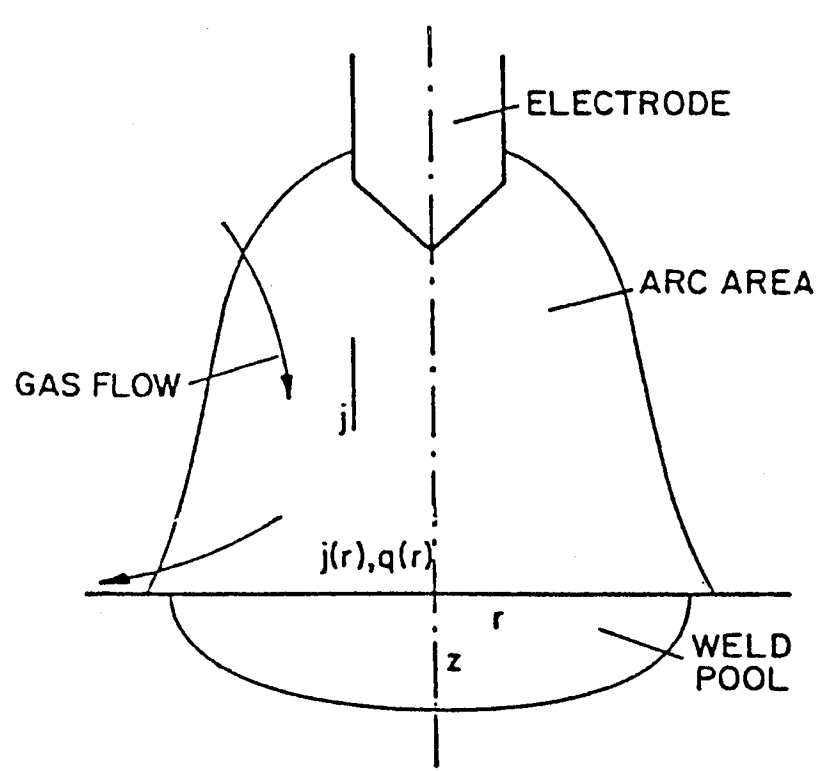

Fig. 11 Schematic of welding arc showing relative size of weld pool, electrode, and arc.

lem can be put into the following differential equations,

Equation of Continuity

$\underset{\sim}{\nabla} \cdot \underline{\sim}=0$

Equation of Motion

$$
\rho(\underset{\sim}{\mathbb{V}} \cdot \underset{\sim}{\nabla}) \underset{\sim}{\mathrm{V}}=-\underset{\sim}{\mathrm{P}}+\mu{\underset{\sim}{2}}_{\sim}^{\mathrm{V}}+\underset{\sim}{\mathrm{Fb}}
$$

The buoyancy and electromagnetic forces are considered in the force term $\mathrm{Fb}$. And the effect of surface tention is taken into account through the boundary condition which is given as,

$$
\mu \frac{\partial \mathrm{Vr}_{\mathrm{r}}}{\partial \mathrm{z}}=-\frac{\partial \gamma}{\partial \mathrm{T}} \frac{\partial \mathrm{T}}{\partial \mathrm{r}}
$$

These governing equations are solved by using F.D.M. Computed temperature and velocity distributions in the weld pool are shown in Fig. 12 and Fig. 13. Two figures in Fig. 12 are the results if all driving forces are considered. On the other hand, Fig. 13 shows results if the surface tension is neglected. From these results we can observe significant effect of surface tension on the flow in the weld pool.

\subsection{Heat transfer in welding arc}

Similar method can be applied to welding arc. The electromagnetic force filed, the velocity field, and the temperature field in DC welding arc is analyzed using F.D.M. by Ushio ${ }^{19)}$. Especially, the velocity profiles and the
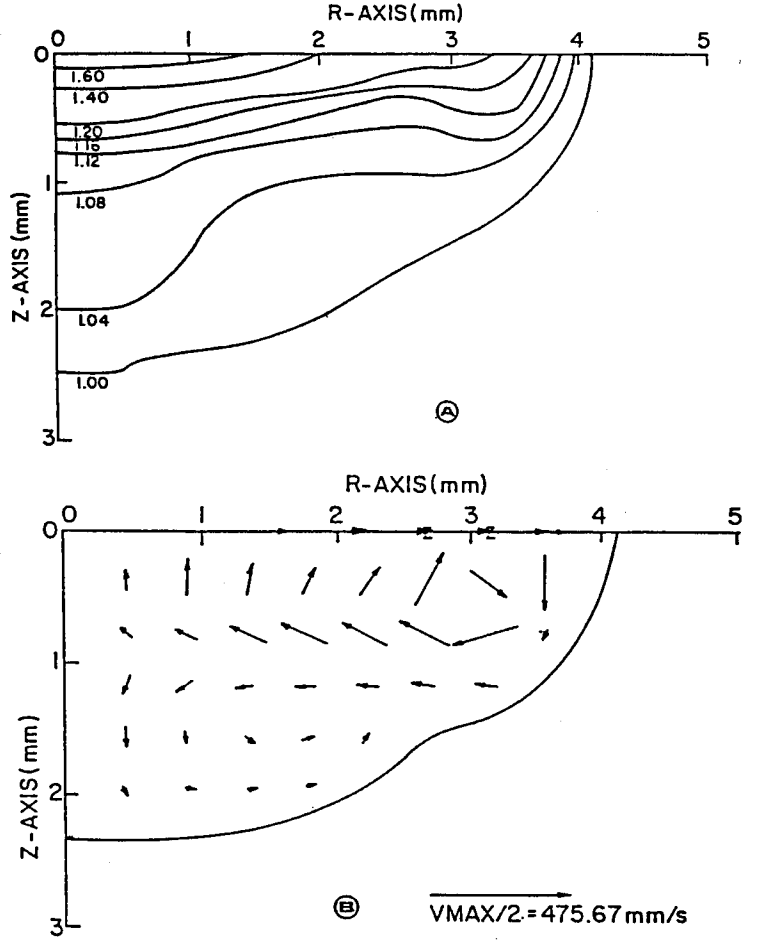

Fig. 12 Computed isotherms and velocity map (considering all driving forces).
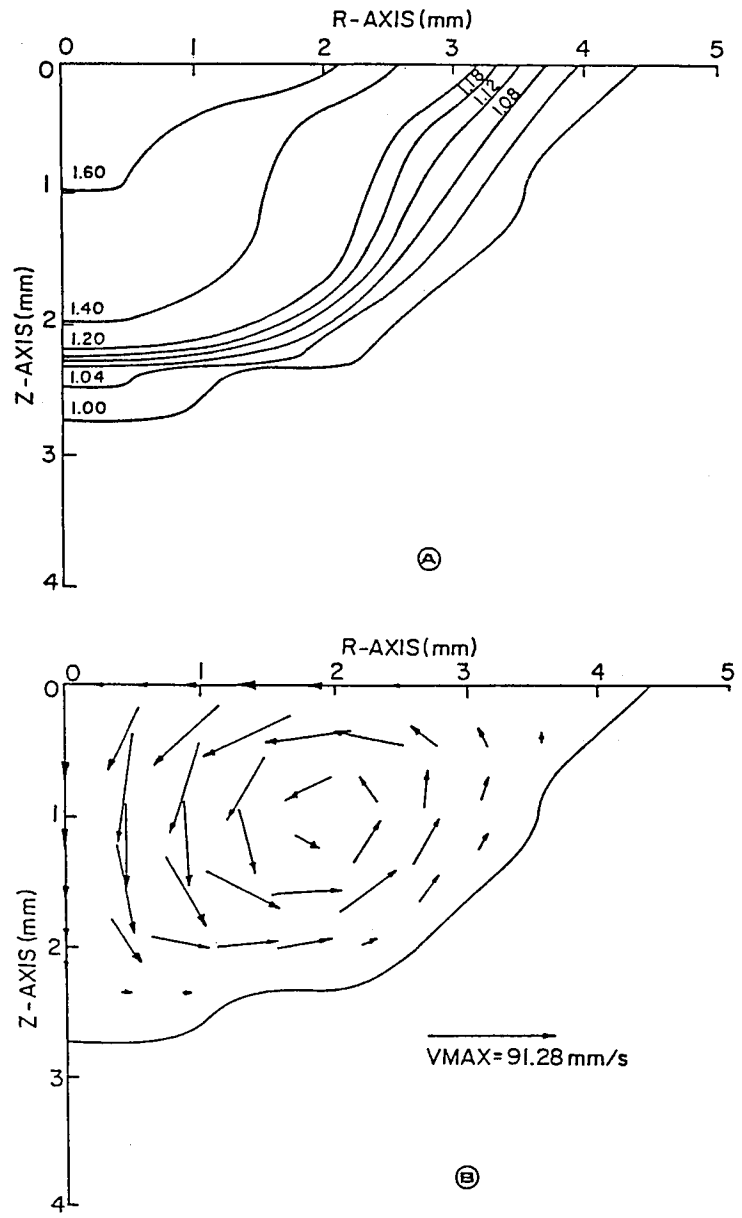

Fig. 13 Computed isotherms and velocity map (without surface tension). 
temperature profiles in the system with various electrode shapes are investigated and compared with experimental results.

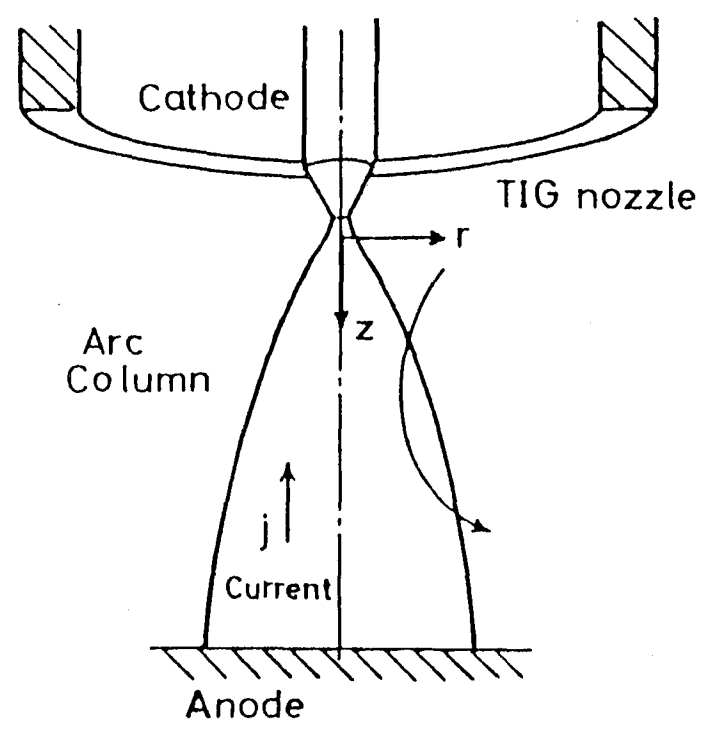

Fig. 14 Schematic drawing of TIG arc model and coordinate system.

Fig. 14 shows a schematic view of TIG arc model discussed in this example. To describe the system in mathematical form, some assumptions or simplifications are introduced. For example, the effect of the atomic collision process, which is extremely complicated, is considered through empirical equations. Under proper assumptions, the system can be described by the following equations,

Equation of Continuity

$\nabla \cdot(\rho \mathrm{V})=0$

Equation of Motion

$$
\rho(\mathrm{V} \cdot \nabla) \mathrm{V}=-\nabla \mathrm{P}-\nabla \tau+\mathrm{F}
$$

Themal Energy Balance Equation.

$$
\rho(\mathrm{V} \cdot \nabla \mathrm{h})=\nabla \cdot \mathrm{K}_{\mathrm{eff}} \nabla \mathrm{T}+\mathrm{S}_{\mathrm{T}}
$$

The computed flow pattern is shown by stream lines in Fig. 15. Fig. 16 shows the changes in heat input distributions for three different shapes of cathode tips.

\subsection{Hydrogen diffusion in weld joints}

As commonly understood, hydrogen plays an important role in cold cracking of welded joints. However, it is also known that hydrogen exhibits anomalous behavior at

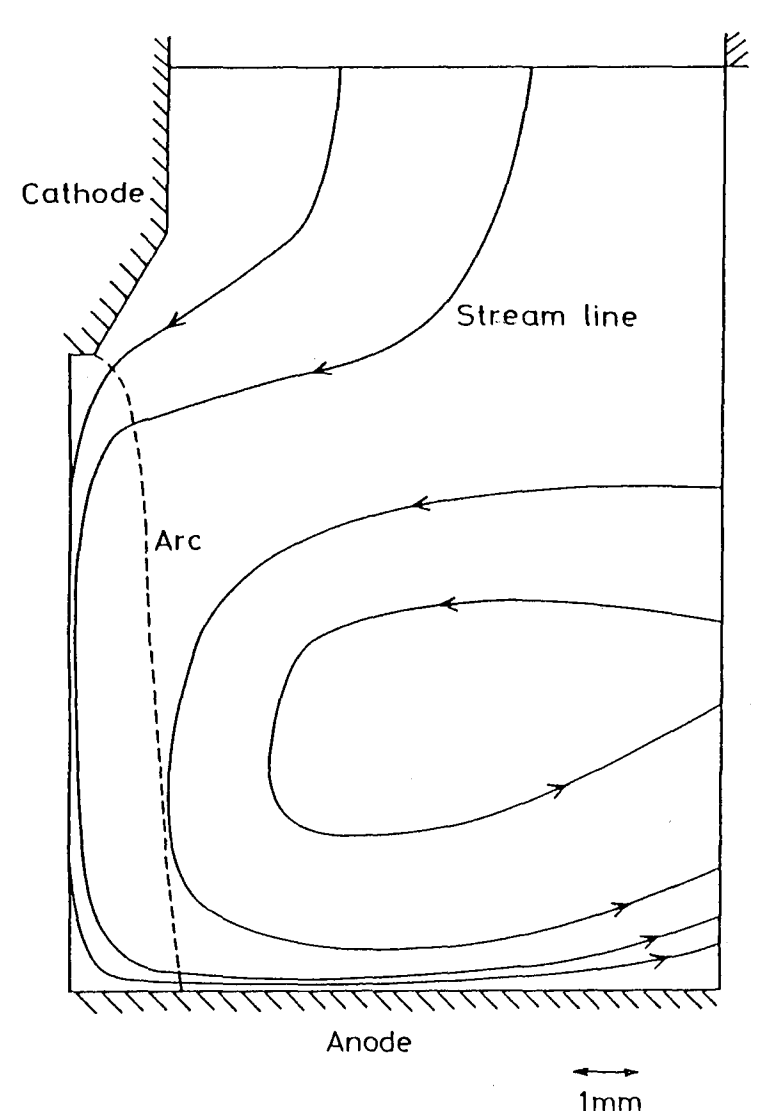

Fig. 15 Computed flow pattern under the condition of $200 \mathrm{~A}$ argon arc.

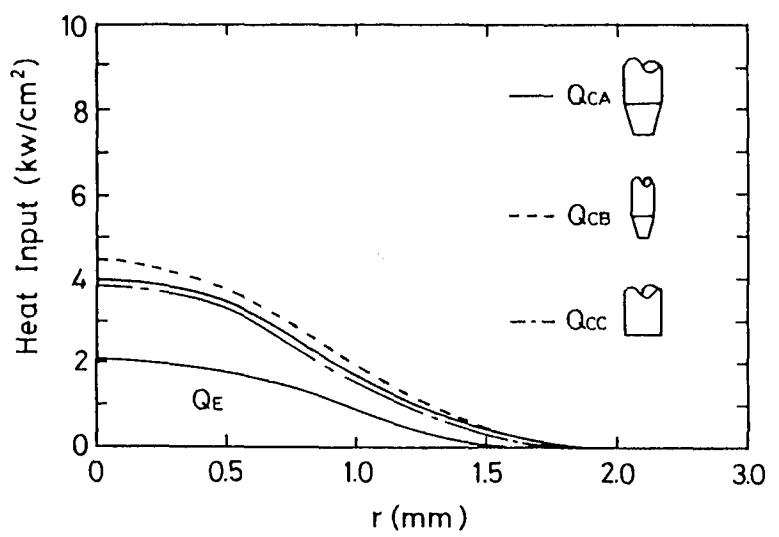

Fig. 16 Comparison of heat inputs in cases of various electrode.

around room temperature and it is considered as the result of trapping of hydrogen by defects. Mathematical models counting the effect of traps are proposed by $\mathrm{McNabb}^{20}$ ). His models can be categorized into two types in which local equilibrium between hydrogen in lattice and traps is postulated and is not postulated.

Anderson $^{21)}$ applied the local equilibrium model to a bead-on-plate weld. In this example, diffusion and trapping of hydrogen is simulated by F.E.M. based on the differential equation given as follows,

$$
\frac{\partial \mathrm{H}_{\ell}}{\partial \mathrm{t}}+\frac{\partial \mathrm{H}_{\mathrm{t}}}{\partial \mathrm{t}}=\frac{\partial}{\partial \mathrm{X}_{\mathrm{i}}}\left(\mathrm{D} \frac{\partial \mathrm{H}_{\ell}}{\partial \mathrm{X}_{\mathrm{i}}}\right)-
$$




$$
\frac{\partial}{\partial \mathrm{X}_{\mathrm{i}}}\left(\mathrm{H}_{\ell} \frac{\mathrm{D}}{\mathrm{RT}}\left(\mathrm{V} \frac{\partial \sigma}{\partial \mathrm{X}_{\mathrm{i}}}-\frac{\mathrm{Q}^{+}}{\mathrm{T}} \frac{\partial \mathrm{T}}{\partial \mathrm{X}_{\mathrm{i}}}\right)\right)
$$

Hydrogen in steel is assumed to be separated into Hydrogen in lattice " $\mathrm{H}_{\ell}$ " and trapped Hydrogen " $\mathrm{H}_{\mathrm{t}}$ ". Further, trapped Hydrogen is assumed to be a sum of Hydrogen trapped in void " $\mathrm{H}_{\mathrm{V}}$ " and that trapped in irreversible trap " $\mathrm{H}_{\mathrm{n}}$ ". Also, the effects of stress, thermotransport, and plastic strain on Hydrogen distribution are considered in this model.

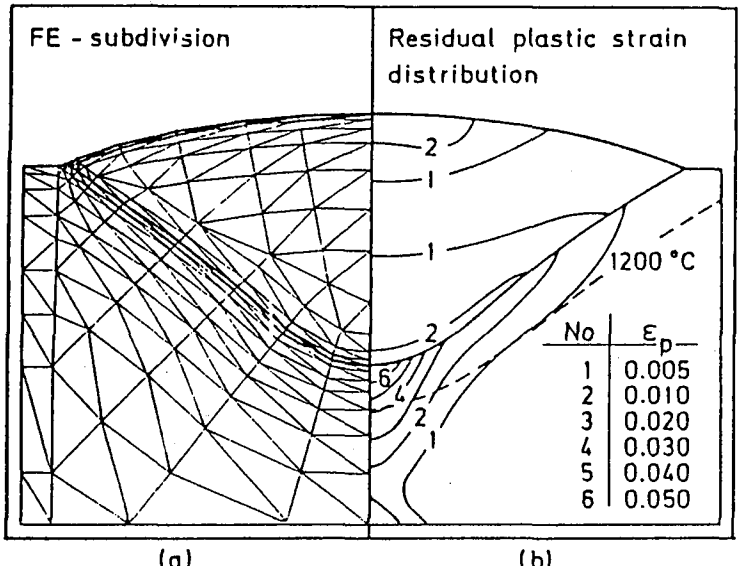

Fig. 17 (a) FE-subdivision, (b) Contour map of calculated residual plastic strain distribution.

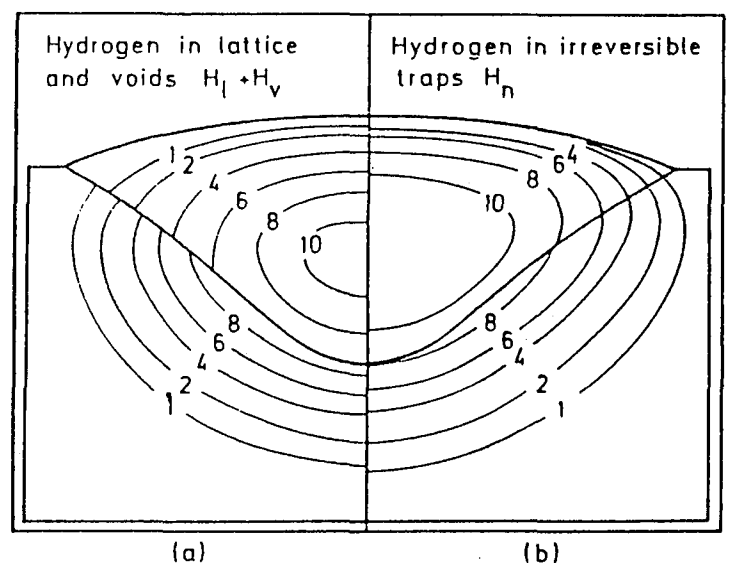

Fig. 18 (a) Calculated distribution of hydrogen in voids and lattice after $350 \mathrm{~s}$,

(b) Calculated distribution of residual hydrogen.

Fig. 17 shows the Finite Element Mesh and the computed plastic strain distribution. The computed diffusible Hydrogen distribution and the distribution of Hydrogen trapped in irreversible trap are presented in Fig. 18.

Among the recent theoretical development on hydrogen in metal, Murayama ${ }^{22)}$ discussed the effect of plastic deformation on hydrogen permeation. In his model, hydrogen transported by moving dislocations is considered.

\subsection{High power electron beams in atmosphere}

If an electron beam is used for cutting and welding in air, the scattering property of the beam is a very important problem. Scattering of particles is considered as a random process. Thus, Monte-Carlo method is a very suitable numerical method for this type of problems. Smith ${ }^{23)}$ has studied the scattering of electron beam in different cases using Monte-Carlo method. Fig. 19 shows

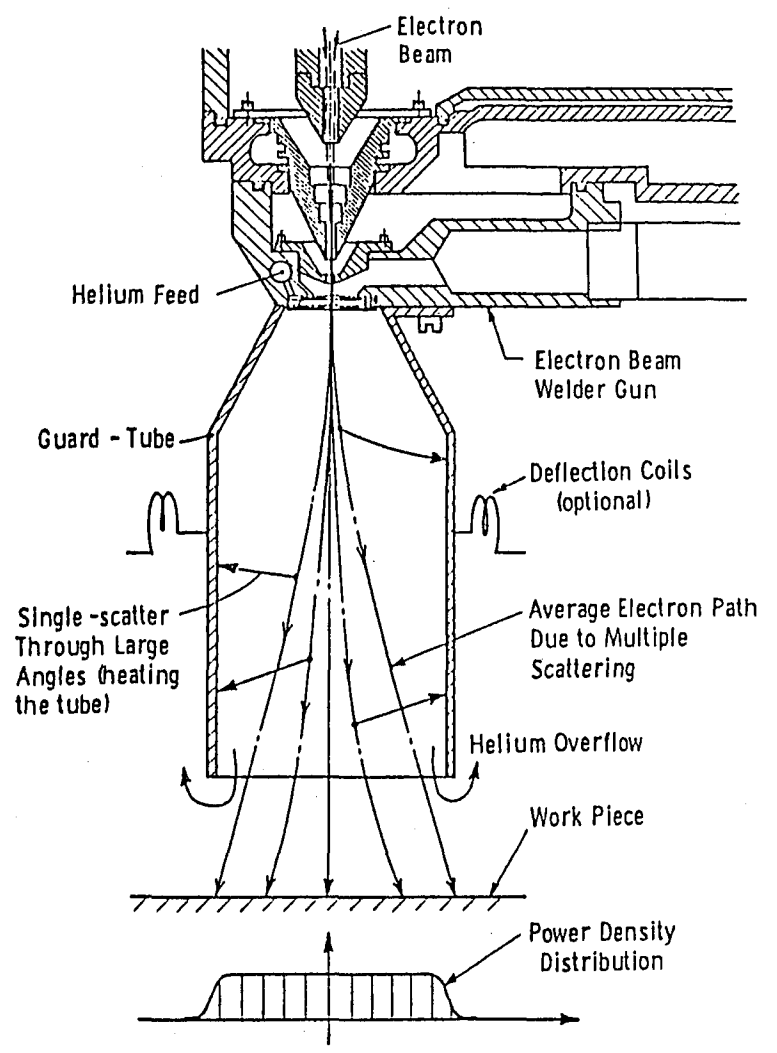

Fig. 19 Profile of electron gun.

a profile of electron gun. The computed trajectories of scattered electron are shown in Fig. 20. From such simulation, the degradation of the beam power with the distance from the focus for various atmosphere is predicted.

\subsection{Automatic recognition of weld defects}

A radiographic test is commonly used as the nondestructive inspection of welded joints. This inspection usually requires a license. However, human judgement may involve some variations among inspectors. To achieve consistent and reliable inspections, digital image processing technique is introduced by Inoue ${ }^{24)}$. Fig. 21 shows a block diagram of the system. This system consists of two parts. The first part is a learning system and the second part is an automatic sorting system in which unclassified defect is classified. In the learning process, radiographic image with classified defect is supplied to the computer. Then the feature of the defect is extracted through digital image processing, and stored in data base. 


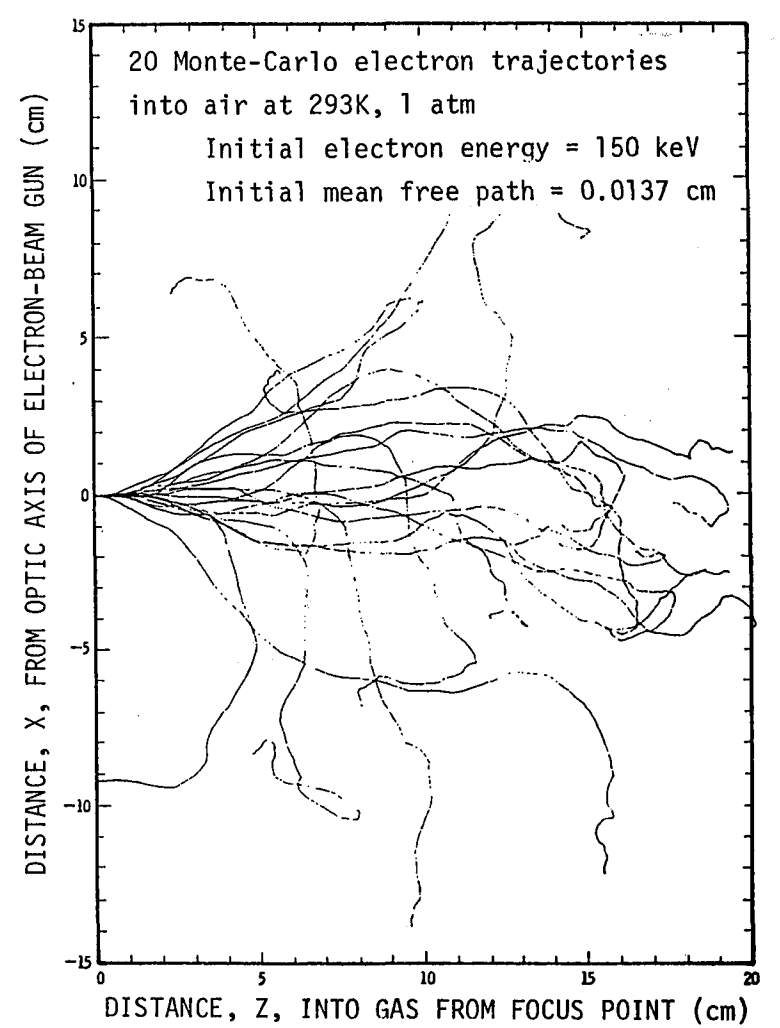

Fig. 20 Typical electron trajectories in room-temperature air.

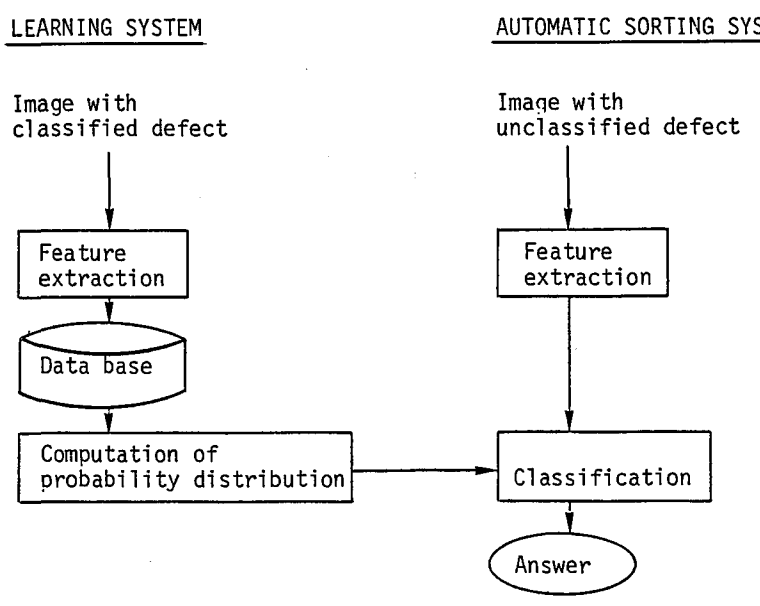

Fig. 21 Block diagram of image data processing.

Using the accumulated data, probability distribution for individual defect type is computed. This probability distribution is used for classifying unknown defects.

\subsection{Personal and pocket computers in welding engineering}

Personal computers are available even in small factories. They may be used for practical design works. Okada ${ }^{25)}$ developed a personal computer system to obtain an optimum welding condition through heat conduction simulations. Special feature of this system is that experimental data, such as material constants and CCT diagrams for the existing steels is stored in the data base.
If one welding condition is chosen, thermal cycle during welding and the shape of penetration and $\mathrm{HAZ}$ are computed. Furthermore hardness and microstructure are determined by consulting proper CCT diagram and other information stored in the data base. The results are displayed on CRT and the engineer can decide whether the chosen welding condition is proper or not. If not, the same process is repeated interactively until the optimum welding condition is found. Similar system for a programmable pocket computer is reported by Seyffarth ${ }^{26)}$.

\section{Problems to be Overcome}

As it is seen from the typical examples reviewed in the previous chapter, numerical analysis has been applied to variety of fields in welding research and our understanding of individual phenomena has been significantly deepened. However, many problems are still beyond our present knowledge' of numerical analysis. When we tackle these problem, we have to face the following questions to achieve meaningful research.

a) What are the major factors which govern the problem?

b) What is the proper mathematical description?

c) How to idealize the boundary and initial conditions?

d) How to define material constants?

e) How to count nonlinear effects and interactions?

In addition to these, proper numerical method has to be chosen to ensure adequate accuracy and realistic computation cost.

\section{Conclusion}

Because of the complexities of our problems, most of theoretical researches were limited to qualitative interpretations before computers were introduced. Recent progress in computer technology and numerical analysis has made it possible to simulate complex phenomena and to discuss our problems from the quantitative aspect. As briefly discussed, computers have a great potential to be our useful tools. However, there are some problems to be overcome before we can achieve truely meaningful research. For example, it is necessary to bridge between real phenomena and mathematical models and to define accurate material constants which may be dependent upon several factors, such as temperature, stress, strain, and their rates. To solve these problems, the most importance is tighter cooperation among researchers and engineers who are engaged in experimental work, theoretical development, numerical analysis, and design work.

\section{Acknowledgements}

The authors wish to acknowledge the staffs of Welding 
Research Institute who provided us valuable informations concerning the present review. Also, the authors would like to acknowledge the authors of original papers which are cited as references.

\section{References}

1) Y. Ueda and T. Yamakawa: Analysis of Thermal Elastic-Plastic Stress and Strain During Welding by Finite Element Method, Trans. Japan Welding Soc. Vol. 2, No. 2 (1971), 90-100. Also IIW Doc. X-616-71 (1971).

2) Y. Ueda and T. Yamakawa: Thermal Stress Analysis of Metals with Temperature-dependent Mechanical Properties, Behaviour of Materials, Vol. III (1972), 10-20.

3) Y. Ueda, K. Fukuda, K. Nakacho, E. Takahashi, and K. Sakamoto: Transient and Residual Stresses from Multipass Weld in Very Thick Plates and Their Reduction from Stress Relief Annealing, Proc. The 3rd Int. Conf. on PVT, Part II (ASME), Japan, (1977), 925-933.

4) Y. Fujita and T. Nomoto: Studies on Thermal Elastic-Plastic Problems (1st Report), J. Soc. Naval Architects of Japan, Vol. 130 (Dec. 1971), 183-191 (in Japanese).

5) H.D. Hibbitt and P.V. Marcal: Numerical Thermomechanical model for the welding and subsequent loading of a fabricated structure, Computers and Structures, Vol: 3 (Sep. 1973), 1145-1174.

6) Y. Ueda, K. Fukuda, and K. Nakacho: Basic Procedure in analysis and Measurement of Welding Residual Stresses by Finite Element Method, Int. Conf. on Residual Stresses in Welded Construction and Their Effects, The Welding Institute, Nov. 1977, 27-37.

7) T. Inoue and Z.G. Wang: High-temperature Behavior of Steels with Phase Transformation and the Simulation of Quenching and Welding Processes, Proc. 4th Int. Conf. Mechanical Behavior of Materials, Stockholm (1983), 1015.

8) Z.G. Wang and T. Inoue: A Viscoplastic Constitutive Relationship with Phase Transformation and the Application to the Process of Welding, Proc. Int. Symp. Calculation of Internal Stresses in Heat Treatment of Metallic Materials, Linkoping (1984).

9) T. Inoue and Z.G. Wang: Coupling Phenomena Between Stress, Temperature and Metallic Structures in the Process with Phase Transformation, Proc. Int. Symp. Calculation of Internal Stresses in Heat Treatment of Metallic Materials, Linkoping (1984).

10) Y. Ueda, K. Fukuda, K. Nakacho and S. Endo: A New Measuring Method of Residual Stresses with the Aid of Finite Element Method and Reliability of Estimated Values, J. Soc. Narval Architects of Japan, Vol. 138 (1975), 499-507 (in Japanese).

11) Y. Ueda, K. Fukuda, K. Nakacho and S. Endo: A New Measuring Method of Residual Stresses with the Aid of Finite Element Method and Reliability of Estimated Values, Trans. of JWRI, Vol. 4, No. 2 (1975), 19-27.
12) Y. Ueda, K. Fukuda, and M. Tanigawa: New Measuring Method of Three Dimensional Residual Stresses Based on Theory of Inherent Strain, Trnas. of JWRI, Vol. 8, No. 2 (1979), 89-96.

13) Y. Ueda, K. Fukuda, and M. Fukuda: A Measuring theory of three Dimensional Residual Stresses in Long Welded Joints ( $\mathrm{L}_{\mathrm{y}}$ Method and $\mathrm{L}_{\mathrm{z}}$ Method), Trans. of JWRI, Vol. 12, No. 1 (1983), 113-122.

14) Y. Ueda, K. Fukuda, I. Nishimura, H. Iiyama, N. Chiba, and M. Fukuda: Three Dimensional Cold Bending and Welding Residual Stresses in Penstock of $80 \mathrm{kgf} / \mathrm{mm}^{2}$ Class High Strength Steel Plate, Trans of JWRI, Vol. 12, No. 2 (1983), 117-126.

15) Y. Ueda, K. Fukuda, Y.C. Kim, and T. Yamazaki: New Measuring Method of Axisymmetric Three Dimensional Residual Stresses Using Inherent Strains as Parameters, Trans. of JWRI, Vol. 13, No. 1 (1984), 105-104.

16) A.H. Dilawari, J. Szekely, and T.W. Eagar: Electromagnetically and Thermally Driven Flow Phenomena in Electroslag Welding, Metallurgical Transactions, Vol. 9B (Sep. 1978), 371-381.

17) G.M. Oreper, T.W. Eagar, and J. Szekely: Convection in Arc Weld Pools, Welding Research Supplement, Nov. 1983, 307312.

18) D.R. Atthey: A Mathematical Model for Fluid Flow in a Weld Pool at High Currents, J. Fluid Mech., Vol. 98 (1980), 787801.

19) M. Ushio and F. Matsuda: Mathematical Modeling of Heat Transfer of Welding Arc (Part 1), Trans. of JWRI, Vol. 11, No. 1 (1982), 7-15.

20) A. McNabb and P.K. Foster: A New Analysis of the Diffusion of Hydrogen in Iron and Ferritic Steels, Trans. AIME, Vol. 227 (Jun. 1963), 618-627.

21) B.A.B. Andersson: Diffusion and Trapping of Hydrogen in a Bead-on-plate Weld, J. Engineering Materials and Technology, Vol. 102 (Jan. 1980), 64-72.

22) K. Maruyama, M. Meshii, and H. Oikawa: Effect of Moving Traps on Hydrogen Transport by Dislocations, Proc. Yamada Conference IV on Dislocation in Solids, Tokyo (Aug. 1984).

23) R.C. Smith and B.W. Schumacher: High Power Electron Beams in Atmosphere, Nuclear Instruments and Methods, Vol. 118 (1974), 1-31.

24) K. Inoue and M. Kobayashi: Automatic Recognition of Weld Defects in Radiographic Test, Trans. of JWRI, Vol. 11, No. 2 (1982), 123-132.

25) A. Okada, T. Kasugai, K. Ei, Y. Muramatsu, K. Hiraoka, and M. Inagaki: Philosophy and Outline of System-Design (Development of Welding Heat Conduction Simulator by Interactive Personal Computer, Report 1), J. Japan Welding Soc., Vol. 2 No. 2, (May 1984), 286-292 (in Japanese).

26) G. Frank and P. Seyffarth: Calculating Mechanical Properties in the Heat-Affected Zone of Welded Joints in Low-Alloy Steels Using a Programmable Pocket Calculator-the Bases of the Mathematical Model, Welding and Cutting Vol. 7 (1983), $32-35$. 